\title{
Proposed New Chemical Classification of Volcanic Rocks
}

\author{
by $B$. Zanettin
}

The IIIGS Commission on Systematics in Petrology has long been engaged in a thorough study and review of the nomenclature of igneous rocks. Its recommendations for the classification of many volcanic and plutonic rocks based on their mineral content have been widely accepted, and work on ultrabasic, ultramatic and metamorphic rocks is in the planning staaes. In this short review the Chairman of the Sutcommission on lgneous Rocks sets out its recent recommendations for a chemical classification of volcanic rocks.

\section{Introduction to the TAS Diagram}

In order to be consistent with the classification of plutonic rocks (Streckeisen, 1978), the Subcommission on the Systematics of Igneous Rocks has agreed that the primary classification of volcanic rocks should be based on their modal composition. However, where this is not possible, as in the case of most volcanics which are glassy or microcrystalline, the Subcommission now recommends the use of chemical parameters plotted on the Total Alkali Silica (TAS) diagram as a basis of classification.

This decision followed careful consideration of the use of the Q'A'P'F' diagram, the normative version of the QAPF modal diagram now widely used for plutonic rocks, (Streckeisen, 1976; Streckeisen and Le Maitre, 1979). Also considered were the AnOr (100An/An + Or) diagram, also based on normative minerals and corresponding to a chemical approximation of the QAPF classification (Rittmann, 1973), and the $R_{1}-R_{2}$ diagram of de la Roche and others (1980) based on atomic numbers. Tests performed on the diagrams that used CIPW norms were affected by the uncertainty in dividing normative albite between alkali feldspar and plagioclase, and the Subcommission decided in favour of the use of simple chemical parameters such as proposed long ago by Harker in his alkali-silica diagram.

The TAS diagram was also chosen because it is favoured by many petrologists (e.g. Bogatikov, Gonshakova and Efremova, 1981; Middlemost, 1972, 1980), because it is useful for separating various rock types (e.g. Cox, Bell and Pankhurst, 1979; Irvine and Baragar, 1971; Le Maitre, 1976), and because $\mathrm{SiO}_{2}$ is now widely used as a parameter to separate several common volcanic rocks (Peccerillo and Taylor, 1976; Hatch, Wells and Wells, 1949). Moreover, the Subcommission prefers a simple classification with straight-line boundaries, and one that permits classification without knowledge of the locality of the sample or the rocks with which it is associated in the field. In short, there should be no element of interpretation, other than that the rock is volcanic.

A first draft of the classification was prepared by a small working group led by $R$. Le Maitre and including G. Bellieni, E. Justin-Visentin, M.J. Le Bas, E.M. Peccerillo, R. Schmid, A. Streckeisen, and the author. A revised version has now been published for the Subcommission by Le Maitre (1984), who provides the criteria and details on which the TAS fields are based.

The essential features of the TAS diagram, shown on Figure 1 , were obtained by using chemical analyses selected from the CLAIR and PETROS data files (Le Maitre, 1982). Accurate classification of volcanic rocks with the TAS diagram is subject to the conditions that specimens should be fresh (preferably with $\mathrm{H}_{2} \mathrm{O}$ and $\mathrm{CO}_{2}$ contents less than $2 \%$ and $0.5 \%$ by weight, respectively), unmetamorphosed and free from crystal accumulation. Chemical analyses should be recalculated to $100 \%$ by weight on $\mathrm{H}_{2} \mathrm{O}$ and $\mathrm{CO}_{2}$ free basis.

\section{Silica Saturation}

On the TAS diagram (Fig. 1) two diverging lines separate three sectors with different degrees of silica saturation in the CIPW norm. Rock compositions plotting in the lower (oversaturated) set (basaltic andesite, andesite, dacite, rhyolite) are almost exclusively quartz-normative, while rock compositions plotting in the upper (undersaturated) set (basanite, tephrite, phonotephrite, tephriphonolite, phonolite) are almost exclusively nepheline-normative. Rock compositions with variable degrees of silica saturation plot within the intermediate set.

For compositions plotting between the heavy lines on Figure 1 , it may be useful to specify values for quartz normative (Qn), olivine-hypersthene normative (Oln) and foid normative (Nen) types. Since these are dependent, at least in part, on the oxidation state of the iron, it is recommended that the ratio of $\mathrm{FeO}$ to $\mathrm{Fe}_{2} \mathrm{O}_{3}$ be used as determined; any modification of this ratio should be clearly stated and justified by the user.

Each of the three sets of fields on the TAS diagram include commonly associated rock types. Generally, the evolutionary trend of comagmatic rocks is subparallel to the boundary lines of the three sets. The transversal lines subdividing the sets into TAS fields may be regarded as approximate lines of equal evolution.

\section{Proposed Classification}

The classification scheme illustrated in Figure 1 is hierarchical. A root name is first obtained. Further subdivision may be made by means of selected chemical criteria, yielding a sub-root name.

Figure 1: The TAS diagram showing root names. The two heavy lines distinguish three sets of fields with different degrees of silica saturation.

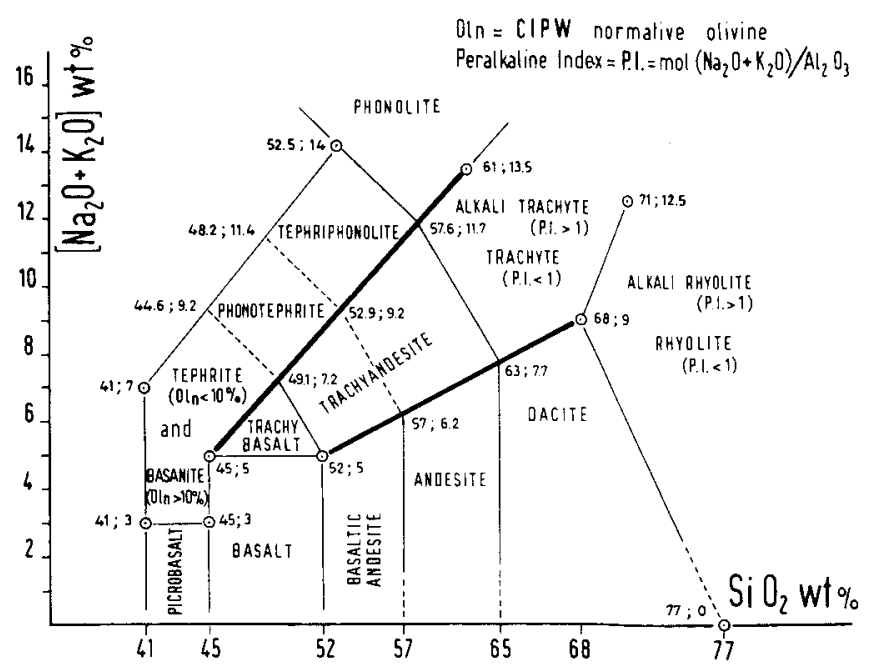

